\title{
OBSERVATIONS OF THE GALACTIC RADIO EMISSION BETWEEN 1.5 AND 10 MHz FROM THE ALOUETTE SATELLITE
}

\author{
by T. R. HARTz \\ (Defence Research Telecommunications Establishment, \\ Defence Research Board, Ottawa, Canada)
}

R fisumf. - Depuis le 29 septembre 1962, le satellite Alouette transporte sur une orbite circulaire d'inclinaison 80,50, d'altitude $1000 \mathrm{~km}$, un récepteur à balayage de fréquence couvrant la bande 0,5 d $12 \mathrm{MHz}$. De la petite portion des données qui a été réduite, on a pu déduire le spectre de l'émission radio galactique entre 1,5 et $5 \mathrm{MHz}:$ mais on n'a pas pu étendre la réduction jusqu'à $10 \mathrm{MHz}$. Bien que le récepteur ne comporte pas d'étalonnuge absolu du gain en vol, les résultats sont assez cohérents pour donner confiance dans la stabilité de l'étalonnage au sol. La plus grande difficulté réside dans l'effet du milieu ionisé sur l'impédance de l'antenne. Pour évaluer ces effets, on a comparé les mesures du rayonnement galactique obtenus dans différents environnements; densité élecironique et champ géomagnétique et extrapolé vers les conditions de l'espace libre. La région du ciel la plus brillante sur 2,3 $\mathbf{M H z}$ est centrée sur le póle galactique sud $\left(1,810^{7}{ }^{\circ} \mathrm{K}\right)$. La région la moins brillante $\left(5,01^{6}{ }^{\circ} \mathrm{K}\right)$ à $2,3 \mathrm{MHz}$ a pour coordonnées $09,00 \mathrm{~h}$ et $+75^{\circ}$. La courbe représentant la température de brillance en fonction de la fréquence présente une pente de - 1,3 à 1,5 MHz, - 1,7 d 2,3 $\mathrm{MHz}$ et - 2,2 d 5,0 MHz.

ABSTRAOT. - Since September 29, 1962, a sweep-frequency receiver covering the range 0.5 to $12 \mathrm{MHz}$ has been operating in a $1000 \mathrm{~km}$ height, $80.5^{\circ}$ inclination orbit about the earth for about 5 hours $a$ day on the average. Only a very small portion of the data has yet been analyzed, and from this the spectrum of the galactic radio emission between 1.5 and $5 \mathrm{MHz}$ has been determined fairly reliably, but it has not been possible from these data to extend this up to $10 \mathrm{MHz}$ with any accuracy. Although there is no provision for absolute gain calibration of the receiver in fight, the data are so consistent as to give confidence to the pre-fight calibration. The greatest uncertainty hinges on the effects of the ionization on the antenna impedances. To evaluate these, galactic noise measurements have been made under a variety of local electron densities and different magnetic field strengths : these values have then been extrapolated to zero electron density and the free space values obtained by this extrapolation procedure are taken as a measure of the galactic emission. At $2.3 \mathrm{MHz}$ the brightest region of the galaxy is centred on the south galactic pole and has a temperature of about $1.8 \times 10^{7} \mathrm{OK}$. The lowest temperature, about $5.0 \times 10^{6} \mathrm{OK}$, at $2.3 \mathrm{MHz}$ was found for the region centred on $R . A .9 \mathrm{hr} .$, dec $+75^{\circ}$. At this same frequency the brightness temperature versus frequency curve has a slope of - 1.7 ; at $1.5 \mathrm{MHz}$ the slope is - 1.3 and at $5.0 \mathrm{MHz}$ the slope is - 2.2.

Pезюме. - С 29 сентября 1962 спутник Заворонок (Alouette) несет по круговон орбите с 80,50 наклона, на высоте $1000 \mathrm{kм}$, приемник с частотной разверткой покрывающей полосу 0,5-12 Мгц. Из небольщой части данньх, которая была сокращена, можно было вывести спектр галактического радиоизлучения между 1,5 и 5 Мгц; но распространить сокращение до 10 Мгц не удалось. Хотя приемник не содержкт абсолютной градуировки усиления в полете, результаты достаточно связны, чтобы доверять стабильности градуировки на земле. Самое большое затруднение заключается в эфффекте понизированной среды на импеданц антенны. Чтобы оценить эти эфффекты, были сравнены измерения галактического излучения, полученпые в различных окружающих средах - электронная плотность и геомагнитное поле - и экстраполированы на условия свободного пространства. Самый яркий участок неба в 2,3 Мгц имеет центром южный галактический полюс $\left(1,8,10^{7} \mathrm{k}^{0}\right)$.

Наименее яркий участок $\left(5,0.10^{6} \kappa^{0}\right)$ в 2,3 Мгц имеет координаты 09,00 я и $+75^{0}$. Кривая, представляющая температуру блеска в зависимости от частоты, имеет наклон - 1,3 в 1,5 Мrц, $-1,7$ в 2,3 Мгц, и $-2,2$ в 5.0 Мгц.

\section{Introdudtion.}

The Alouette I satellite $(1962 \beta \alpha 1)$ has been in operation since September 29, 1962 . It was designed and built in Canada, at the Defence Research Telecommunications Establishment, and was laun- ched under the auspices of the United States National Aeronautios and Space Administration. Intended primarily as an ionospheric top-side sounding satellite, it provides data on the electron number density at and below a height of $1000 \mathrm{~km}$, and on the local magnetic field strength (WARREN, et al. 1963). In addition, because the automaticgain-control voltage from the sounding receiver 
is telemetered to the ground, simultaneous measurements are also made of the background radio noise level. For frequencies less than those that can penetrate the ionospheric $F$ layer, the background noise data contain information on extraterrestrial noise sources. The sweep-frequency receiver covers the range from 0.5 to $12 \mathrm{MHz}$ and for these frequencies the Galaxy and the active Sun are the two strongest noise sources observed with the Alouette equipment. Emissions from the former, of course, are present in the recordings at all times, whereas the solar noise appears only sporadically. The present paper describes the galactic noise observations; the solar noise is discussed in an accompanying paper (HARTZ 1965).

\section{Essmatials of the Rmokiving System.}

Because the system parameters were chosen on the basis of the sounding experiment, the receiving system is not ideal for measurements of galactic noise; nevertheless, it does work satisfactorily and much useful information has been obtained with it. The receiver has a broadband pre-amplifier, followed by a mixer and a $19 \mathrm{MHz}$ intermediate-frequency amplifier. This is followed by a second mixer and a $0.5 \mathrm{MHz}$ second intermediate-frequency amplifier. This arrangement makes for some difficulty at times when the Fregion critical frequency and the D-region absorption are low, as at night, since intermodulation products from ground transmissions produce interference across the whole recording. At other times, however, this is not a problem and good recordings can be made. The receiver has a noise figure of $15 \mathrm{db}$ and a band width of $33 \mathrm{KHz}$.

The antennas are two orthogonal dipoles, of length $46 \mathrm{~m}$ and $23 \mathrm{~m}$, which are both orthogonal to the satellite spin axis. Impedance matching networks are used to shape the frequency response of the antennas, and the network outputs are applied, in parallel, to the receiver as shown dia-

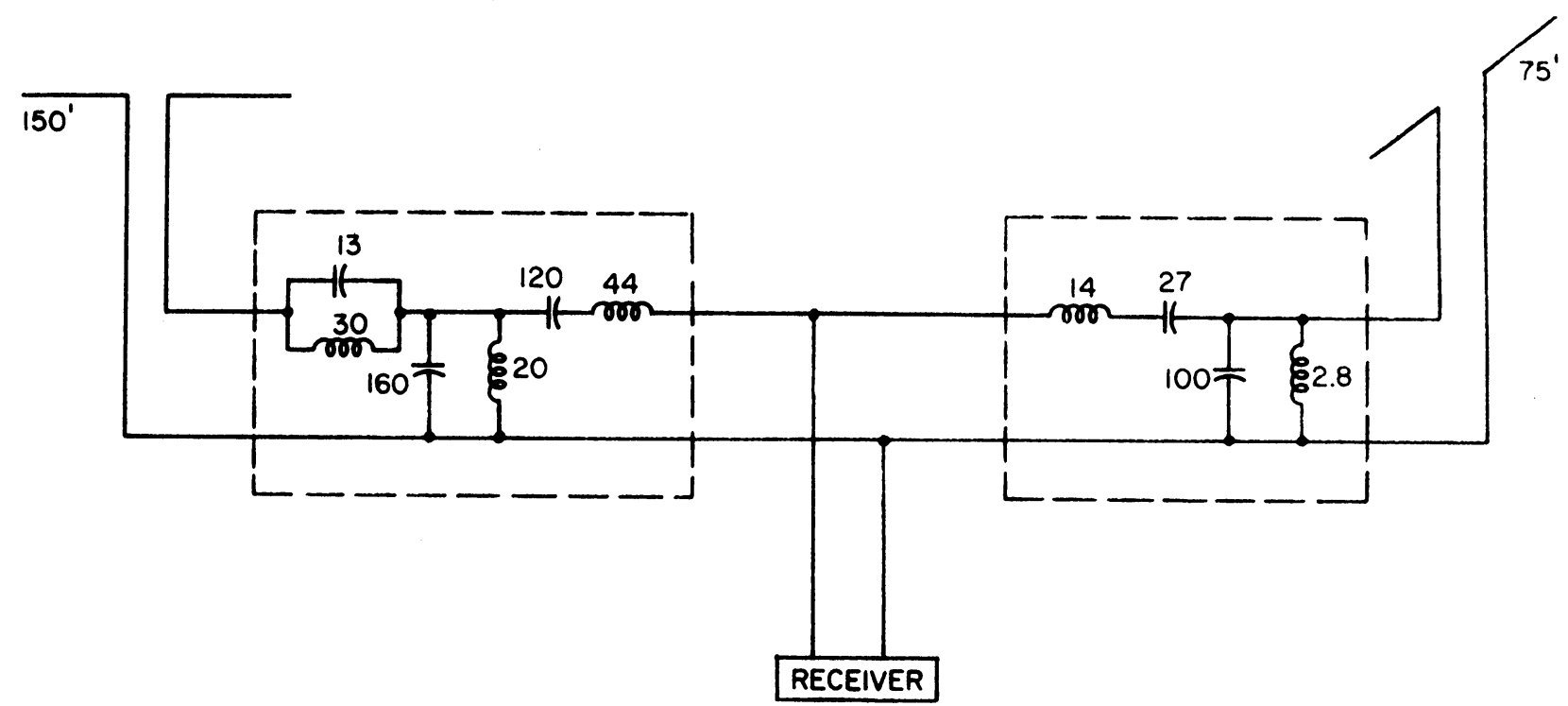

Fra. 1. - Sohematic diagram of the Alouette receiving system showing the orthogonal $150 \mathrm{ft}$. (46 m) and $75 \mathrm{ft}$. (23 m dipoles, and the details of the two antenne matching networks. The capacitors are given in $\mu \mu f$ and the inductance in $\mu \mathrm{H}$.

gramatically in Figure 1. (For simplicity, the transmit-receive switch is not shown; it only introduces a negligibly small capacitance when the sounding transmitter is not active).

Now it is well known that for a lossless system where the receiver impedance is matched to that of a dipole antenna - or to two orthogonal dipoles - the power available from an omni-directional radiation field of random polarization, such as exists in a thermal enclosure of temperature $T$, is given by

$$
\mathrm{P}=\frac{1}{2} k \mathrm{~T} \Delta t .
$$

Here $\Delta f$ is the receiver bandwidth, $k$ is BoutzMaNN's constant, and $T$ is the absolute temperature of the walls of the enclosure. The Alouette system, however, does not have matched impe- 
dances, and in that case the available power can be represented by the relation

$$
\mathbf{P}=\frac{1}{2} k \mathrm{~T} \Delta f \beta,
$$

where $\beta$ is a factor less than unity. Since the antenna impedances are known for free space conditions throughout the frequency range of interest here, the free space response of the antenna system can be computed. Using the impedance notation of Figure 2, it can be shown that

$$
\beta=\frac{4 \mathrm{R}_{3} \mathrm{Z}_{p} \mathrm{Z}_{p}^{*}}{\left(\mathrm{Z}_{3}+\mathrm{Z}_{p}\right)\left(\mathrm{Z}_{3}+\mathrm{Z}_{p}\right)^{*}}\left(\frac{\alpha_{1} \mathrm{R}_{\mathrm{N} 1}}{\mathrm{Z}_{1} \mathrm{Z}_{1}^{*}}+\frac{\alpha_{2} \mathrm{R}_{\mathrm{N} 2}}{\mathrm{Z}_{2} Z_{2}^{*}}\right)
$$

Here $R_{\mathrm{N} 1}, \mathbf{R}_{\mathrm{N} 2}$ and $\mathbf{R}_{3}$ are the resistive components of the complex impedances $Z_{\mathrm{N} 1}, Z_{\mathrm{N} 2}$ and $Z_{3}$, and $\alpha_{1}$ and $\alpha_{2}$ are introduced to account for ohmic loseses in the antennas : they can each be represented as the ratio of the radiation resistance to the sum of the ohmic and radiation resistances.

The computed values of $\beta$ are plotted as a function of frequency in Figure 3 for the free space case. For convenience the respective values are expressed as decibels relative to the idealized situation where $\beta$ is unity. In practice, the Alouette antennas are imbedded in an ionized plasma so that antenna impedances are altered from the free space values, making for different

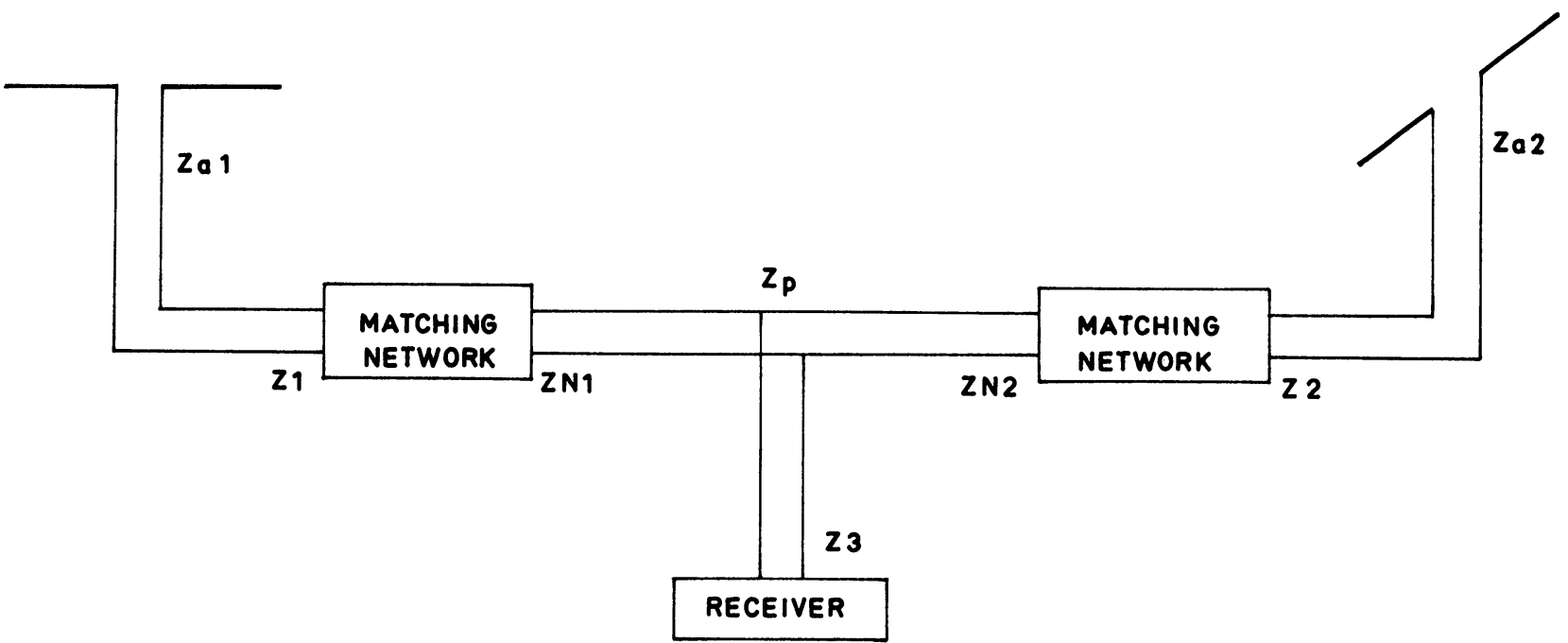

Fra. 2. - Block diagram of the receiving system defining the pertinent impedances, which (except for $Z_{8}$ ) apply when looking towards the antennas.

values of $\beta$ than those of Figure 3. Although there are several theories that describe the impedances of antennas in terms of ionospheric parameters (KOGELNIK 1960, KaISER 1962), it seems that these are most applicable when the length of the antenna is substantially less than the operating wavelength. Since this restriction did not hold for a part of the Alouette frequency range, an empirical approach, as outlined below, was used to reduce the observations to free space conditions, in preference to using the theoretical antenna impedances.

\section{Nature of the Rhcordings.}

In practice Alouette is within range of a telemetry station for about 15 minutes, and some dozen telemetiy stations - most of which are in the North and South American region - have been involved in this progran. The satellite

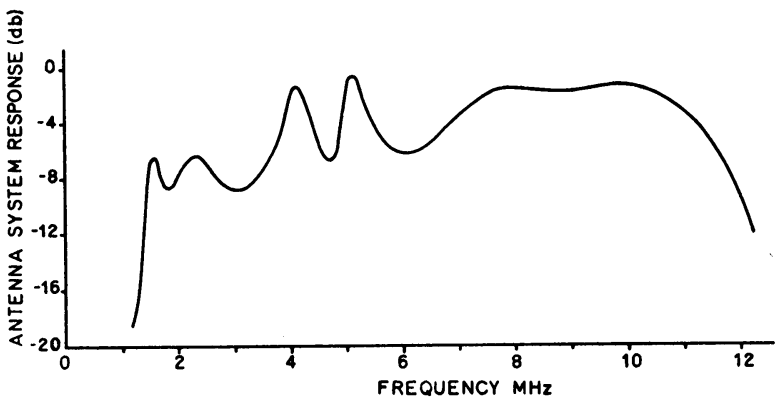

FIG. 3. - Antenna system response as a function of frequency : a free space environment has been assumed for the antennas.

equipment is commanded on by the particular ground station and operates for 10 minutes, then it shuts off automatically. During the operating interval the receiver sweeps in frequency from 0.5 to about $12 \mathrm{MHz}$ and then recycles and repeats the performance with a period of about 18 seconds. One frame of the Automatic-Gain-Control Voltage 


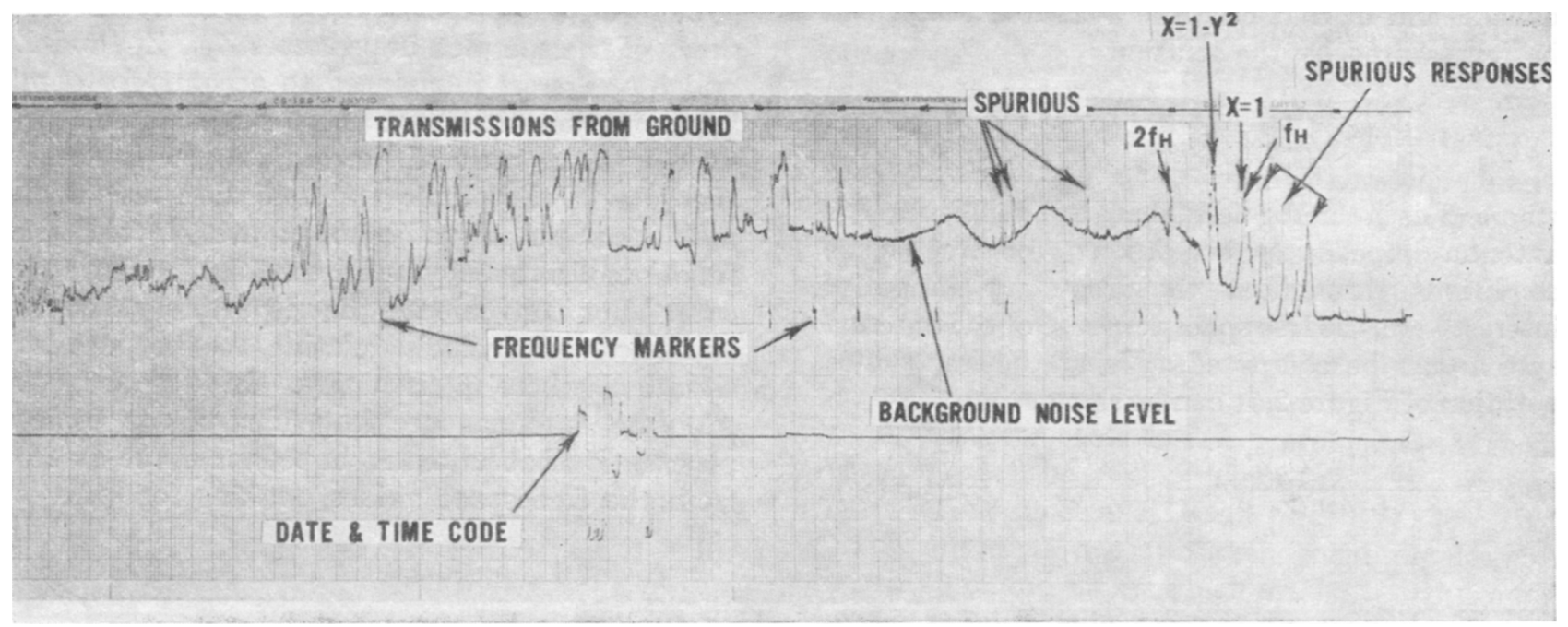

Fra. 4. - A sample recording showing one frame of the Alouette AGC voltage obtained as the receiver sweeps in frequency from 0.5 to $12 \mathrm{MHz}$. Here time and frequency increase from right to left.

record is shown in Figure 4, from which the essential features of the data may be noted.

In this figure frequency (and time) advance trom right to left and frequency markers are displayed on the chart. With the exception of the known spurious equipment responses that appear on the right hand end, the spikes at the low frequencies represent resonances of the ionosphere that are excited by the sounding transmitter. The receiver is inactive during the pulse transmissions, and the automatic-control circuit has an integration time of $20 \mathrm{~ms}$, so that the effects of the echo pulses are not apparent in the recordings of the AGC voltage. Accordingly, the presence of the resonance spikes and occasionally some broadening of the trace under " spread" conditions are the only contaminations introduced by the sounder. This has been verified on a number of occasions by obtaining records from the receiver while the sounding transmitter was alternately switched on and off for successive frames.

At the high frequency end of Figure 4 other spikes appear ; these result from transmissions from the ground above the F-layer critical frequency. The smooth, slowly varying trace in the intermediate frequency range represents the background noise level, which in most cases is the galactic noise level. The amplitude range represented on the chart covers some $50 \mathrm{db}$, from the receiver noise level to saturation, the centre portion of the range being approximately linear in decibels. The receiver gain was calibrated before launch, but absolute power calibration could not be provided in flight. The satellite voltages are stabilized, as is the vehicle temperature to a considerable extent, so that large changes in the gain of the receiver are not expected under normal circumstances. A comparison of data obtained during the 22 months since launch shows sufficient consistency as to suggest that no significant gain changes have yet occurred.

\section{Galactic Noise Mrasurements.}

Using the pre-flight calibration, then, it is possible to scale the galactic noise level as a function of frequency from records such as Figure 4. An example of such a scaling is portrayed by the upper curve of Figure 5, where the plotted data are relative brightness temperature - uncorrected for antenna system response - as obtained from one frame of the recording. From the resonance spikes it is possible to determine the frequencies for which the refractive indices for the ordinary and extraordinary propagation modes vanish, and these are indicated by the dashed vertical lines. If $f_{0}$ and $f_{\mathrm{H}}$ are respectively the plasma and electron gyro-frequencies in the vicinity of the satellite, the two refractive indices,

and

$$
n_{0}=\left[1-\frac{f_{0}^{2}}{f^{2}}\right]^{\frac{1}{2}},
$$

$$
n_{x}=\left[1-\frac{f_{0}^{2}}{f\left(f-f_{\mathrm{H}}\right)}\right]^{\frac{1}{2}},
$$

can be found for any frequency $f$. Moreover, it is 
possible to determine an average or effective refractive index, $n$, from the medium surrounding the satellite in the manner described by CHAPMAN (1961).

As indicated by the upper curve in Figure 5, data are not obtained at frequencies close to the ionospheric resonances since $n$ becomes small and the unknown variation of $n$ with height above the satellite may make for excessive errors. Because the effective antenna aperture is related to $n$ (to a first approximation, $\operatorname{Sin} \theta=n$, where $\theta$ is the half-cone angle), this means that, in practice, the observations have been limited to large antenna apertures, usually to $\theta \geqslant 50^{\circ}$.

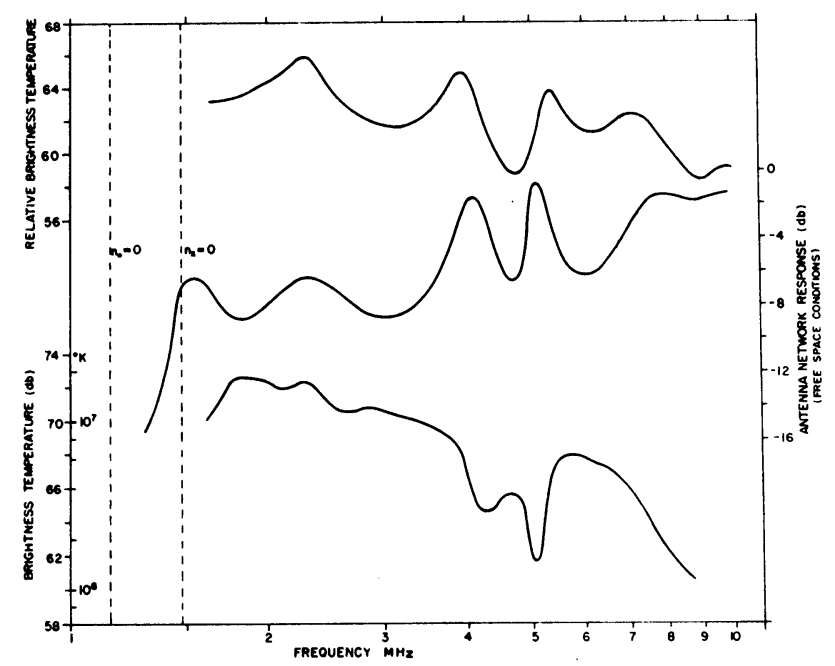

Fra. 5. - The result of scaling one frame of the AGC voltage recording. The upper curve represents the gelactic brightness temperature, uncorrected for antenna system response, obtained from the record; also shown are the frequencies for the zero refractive indices at the satellite for the ordinary and extraordinary propagation modes. The middle curve shows the free-space antenna network response, and the lower curve shows the result of subtracting the two upper curves.

The middle curve of Figure 5 is a replot of Figure 3, giving the antenna system response for free space conditions for convenient reference here. The upper curve, it will be recalled, was scaled from the noise levels measured when the antennas are imbedded in a plasma. A first order approximation to the galactic noise temperature may be obtained by simple subtraction of the two upper curves, resulting in the lower curve of Figure 5. Clearly, a better approximation would result if either the antenna system response were known for the actual operating conditions, or if the measurements of galactic noise levels could be extrapolated to free space conditions.
The latter alternative has been adopted bere and the treatment of the actual observations has proceeded along the lines outlined below.

Curves sueh as the upper one in Figure 5 have been obtained for a wide range of local electron number densities and for different local magnetic field strengths. No apparent dependence on the orientation of the satellite antennas was found in these data, nor was there any significant dependence on the local magnetic field strength except when the observing frequency approached that for $n_{x}=0$. A dependence on the local electron number density, however, was noted in the data. Accordingly, the value of the relative brightness temperature for a particular pass at a chosen frequency was normalized on the value at $2.3 \mathrm{MHz}$ for that same pass and plotted as a function of electron density. This was done for all the passes scaled.

This process was repeated for other frequencies and a family of curves - one for each particular frequency - was produced : this is shown in Figure 6. In each crse a smooth curve, having a shape closely similar to that of its adjacent neighbour, is drawn through the data points and extrapolated to zero electron density. For the lower half of the frequency range the errors involved in the extrapolation process are thought to be relatively small, but for the upper half this is not the case and only a maximum value (at best) for the intercept would appear to be indicated.

The resulting intercept values of the relative noise power for the particular frequencies have been taken as corresponding to free space conditions. Combining these values with those from Figure 3 for the free space antenna system response, one obtains values for the relative galactic brightness temperature as a function of frequency. These are plotted in Figure 7, together with estimated error limits - as applicable - that allow for scatter in the observations as well as for uncertainties in the extrapolation process.

This curve is to be taken as representative of medium and high galactic latitudes and any fine detail in these regions has been smoothed out because of the large antenna apertures involved.

Figure 7 indicates that between 1.5 and about $5 \mathrm{MHz}$ fairly reliable data have been obtained, but this is not so between 5 and $10 \mathrm{MHz}$ for there, only an upper limit at best can be indicated. As drawn the curve has been fitted to the data points below $5 \mathrm{MHz}$ and then extrapolated to $10 \mathrm{MHz}$ with only a very gradual increase in slope.

These plotted data represent relative brightness 

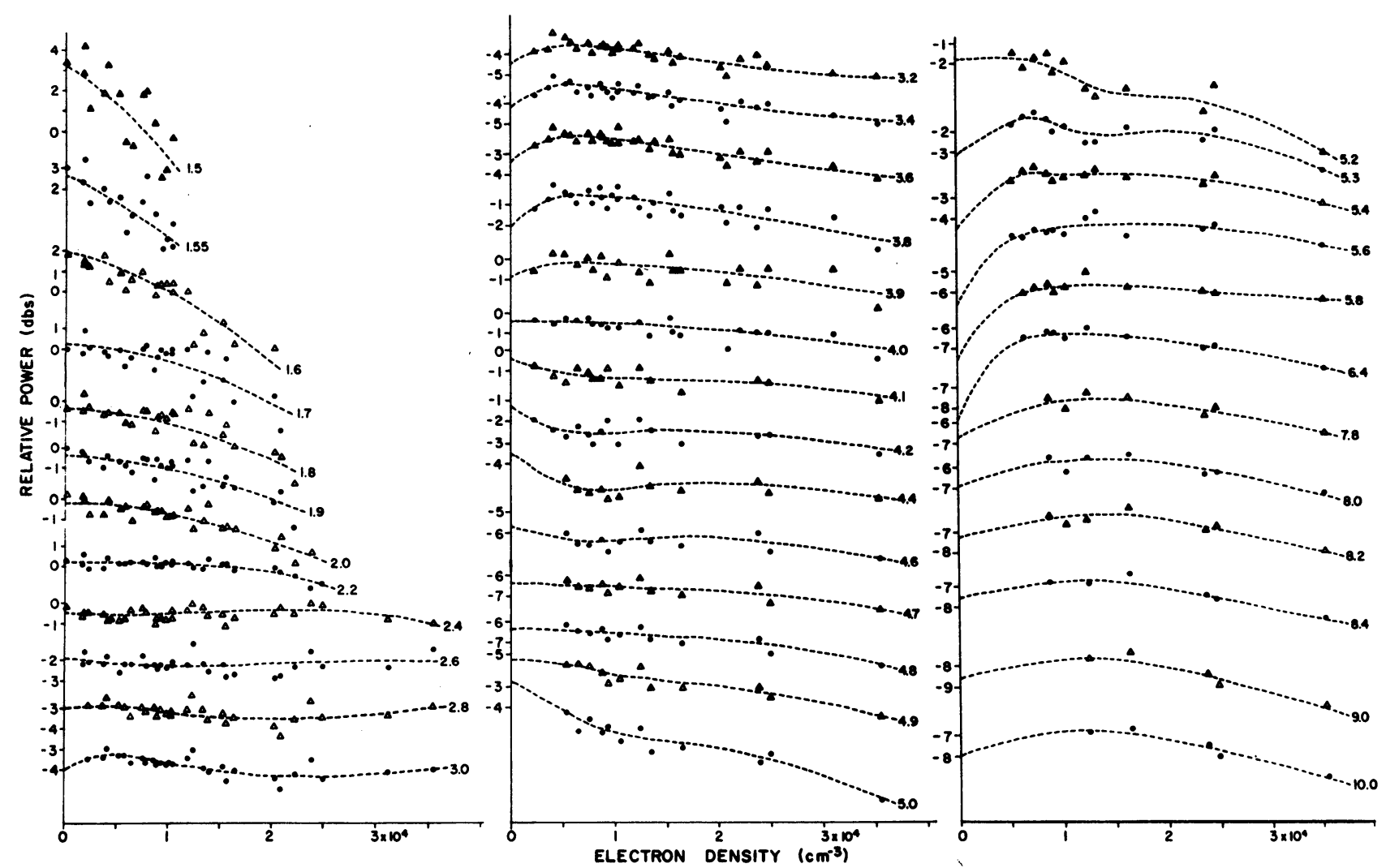

F1G. 6. - A family of curves, each member of which shows for a particular frequency, as indicated, the variation of relative received noise power with electron density in the vicinity of the satellite. The intercept values are representative of free space conditions, and can be used with the free space antenna response to yield the galactic spectrum.

temperatures, which can be converted to relative flux densities by multiplying by the square of the frequency. The curve obtained in this manner has been shown to have a slope that differs significantly from thatfound by EurTs, WATHRWORTH and BesSHLL (1962) from ground based measurements : the discrepancy is of such a nature as to suggest that the effects of ionospheric absorption might not have been entirely removed from the EurIs et al. data (HARTz 1964).

These differences can be seen as well in Figure 8. Here are plotted absolute data obtained from Alouette as well as from other sources. The Alouette data are shown as smooth curves that give the noise spectra for three regions in the Galaxy; those regions are centred on the south and north galactic poles and on RA 9h , dec. $+75^{\circ}$. Shown for comparison are the ground based observations above $10 \mathrm{MHz}$ from the north galactic pole and the galactic anti-centre (TURTLE 1963, TURTLE et al. 1962), the ground based observations of Eurss et al. for the south galactic halo, the satellite measurement of CHAPMaN (1961) of the south galactic halo, and the rocket observations of WALSH, HADDOCE and Schulte (1963) for the region containing the anti-centre.

In the Alouette data the maximum values were obtained from the region centred approximately on the south galactic pole, and the minimum from a region centred approximately on RA 9h ., dec $+75^{\circ}$. $\left(l\right.$ II $\sim 140^{\circ}, b$ II $\left.\sim 40^{\circ}\right)$. It is interesting to note that the location of this latter region compares favorably with the minimum region found by TURTLE and BALDWIN (1962) with much better resolution. At $2.3 \mathrm{MHz}$ the brightness temperatures from these two regions are respectively $1.8 \times 10^{7} \mathrm{oK}$ and $5.0 \times 10^{6} \mathrm{oK}$. (The corresponding flux densities are $3.7 \times 10^{-19}$ and $1.0 \times 10^{-19} \mathrm{Wm}^{-2} \mathrm{~Hz}^{-1}$.) The comparable region centred on the north galactic pole has a temperature of $1.1 \times 10^{7} \mathrm{oK}$ (corresponding to $2.3 \times 10^{-19} \mathrm{Wm}^{-2} \mathrm{~Hz}^{-1}$, whereas the regions centred on the galactic centre and the anti-centre have temperatures of $8.0 \times 10^{6} \mathrm{oK}$ and $1.3 \times 10^{7} \mathrm{oK}\left(1.7 \times 10^{-19} \mathrm{Wm}^{-2} \mathrm{~Hz}^{-1}\right.$ and $2.7 \times 10^{-19} \mathrm{Wm}^{-2} \mathrm{~Hz}^{-1}$ respectively at this 


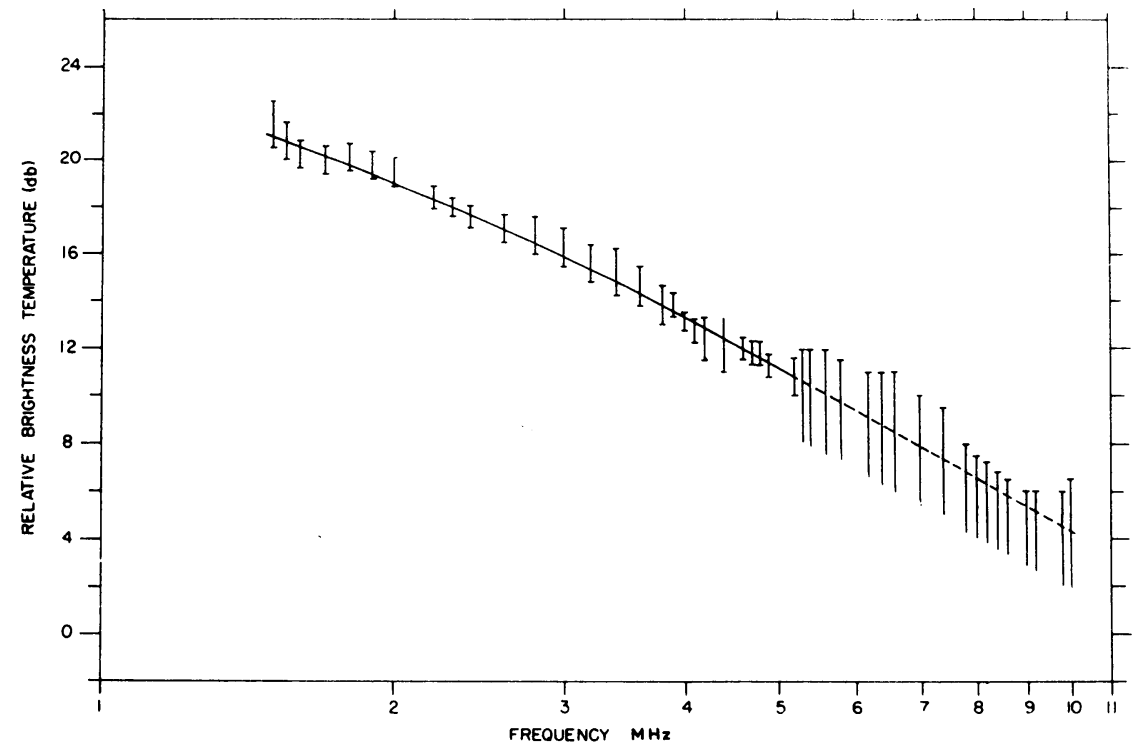

lia 7 - Relative galactic brightness temperature as a function of frequency.

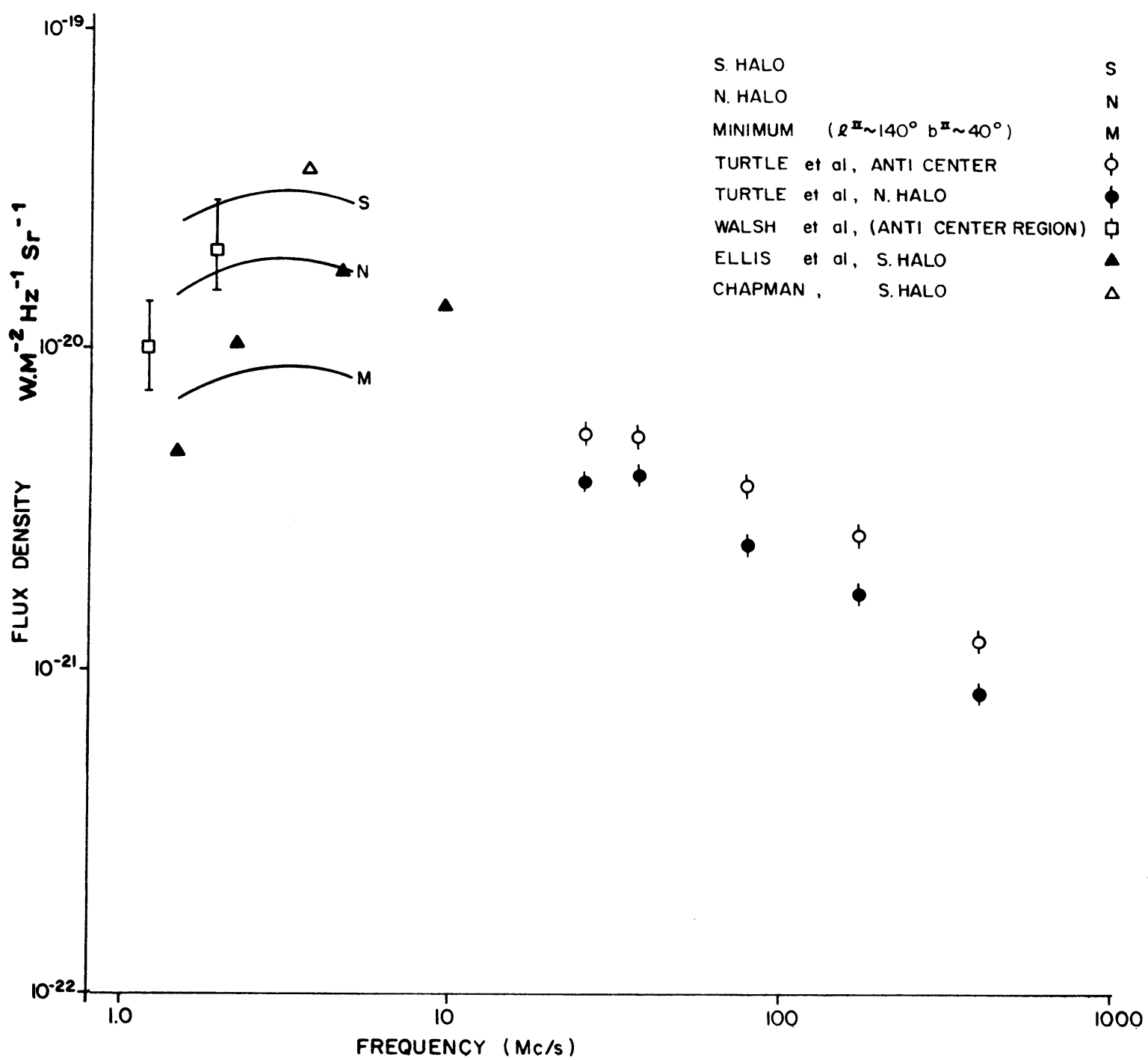

Fia. 8. - Composite diagram showing the variation of the galactic radiation flux density as a function of frequency, as determined by various observers, and for several different regions of the galaxy. The Alouette results are shown as thrae curves, of which two represent the maximum and minimum values found in the data, 
same frequency. It will be recalled that the regions included in each case are rather extensive since the effective antenna aperture is at least $100^{\circ}$ in width at $2.3 \mathrm{MHz}$ under the conditions of measurement.

Manuscrit reçu le 30 aoult.

\section{REFERENCES}

Chapman J. H., 1961, Space Research, II North Holland Pub. Co., Amsterdam, 597.

Ellis G. R. A., WATERWORTH M. D. and Bessell M., 1962, Nature, 196, 1079.

HaRTz T. R., 1964, Nature, 203, 173.

HARTZ T. R., 1965, Ann. d'Astro., 27, p. 839

KAISER T. R., 1962, Planet. Space Sci., 8, 639.

KoGELNIK H., 1960, J. Res. N. B. S., 64:D, 515.

TurTle A. J., 1963, Mon. Not. Roy. Ast. Soc., 126, 405.
Tortle A. J. and Baldwin J. E., 1962, Mon. Not. Roy. Ast. Soc., 124, 459.

Turtle A. J., Pugh J. F., Kenderdine S. and Pauliny-Toth I. I. K., 1962, Mon. Not. Roy. Ast. Soc., 124, 297.

Walsh D., HadDock F. T. and SchULte H. F., 1964, Space Research, IV, North Holland Pub. Co., Amsterdam 935.

WarRen E. S., King J. W., KNecht R. W. and VAN ZANDT T. E., 1963, Nature, 197, 636. 